\title{
DVIBURIS AORTOS VOŽTUVAS: ETIOLOGIJA, DIAGNOSTIKA, CHIRURGINIS GYDYMAS
}

\author{
Dainius Karčiauskas, Viktorija Zieniūtè \\ Lietuvos sveikatos moksly universiteto Medicinos akademijos Medicinos fakultetas
}

Raktažodžiai: dviburis aortos vožtuvas, ịimta širdies yda, infekcinis endokarditas, širdies chirurgija.

\begin{abstract}
Santrauka
Straipsnyje apžvelgiami dviburio aortos vožtuvo (DAV) etiologiniai veiksniai, diagnostikos ir chirurginio gydymo galimybès. Naujausios mokslinès literatūros paieška atlikta PubMed ir UpToDate mokslinèse duomenų bazèse. I sisteminę apžvalgą įtraukta 30 straipsnių nagrinėjama tema. Tyrimo rezultatai atskleide, kad DAV yra viena dažniausių įgimtų širdies ydų, kuri gali būti izoliuota patologija arba kartu su kitomis igimtomis kardiovaskulinès sistemos ydomis bei genetiniais sindromais. DAV morfologija yra hemodinamiškai svarbi, nes lemia turbulencinès kraujo tẻkmès per vožtuvą atsiradimą ir sukelia struktūrinius (histologinius) pokyčius aortos sienelejje. Ilgą laiką funkciškai normalus DAV simptomų nesukelia, tačiau ilgainiui gali susiformuoti restrikcinis aortos vožtuvo (AV) buriu pažeidimas - stenozė ar nesandarumas, kartu su aortos šaknies pažaida, reikalaujančia chirurginio gydymo. Pirmaeilis tyrimas DAV morfologijai nustatyti yra dvimatis (2D) echokardiografinis ištyrimas per krūtinès ląstą. Šiuolaikinejje klinikinejje praktikoje didesnis dèmesys skiriamas AV išsaugančioms operacijoms, esant AV nesandarumui bei DAV morfologijai dèl mažesnių su vožtuvais susijusių komplikacijų ir geresnio išgyvenamumo rodiklių, nesant viso gyvenimo trukmès terapijos antikoaguliantais poreikio.
\end{abstract}

\section{Ivadas}

Dviburis aortos vožtuvas (DAV) yra viena dažniausių igimtų širdies ydų, kuri pasireiškia 0,5-2 proc. bendrosios populiacijos [1,2]. DAV gali būti izoliuota sporadinè patologija arba kartu su kitomis igimtomis kardiovaskulinès sistemos ydomis (aortos koarktacija, skilvelių pertvaros defektas, atviras arterinis latakas) ir (ar) aortopatiniais sindromais su kitomis genetinėmis ligomis - Turner sindromu $[3,4]$. Dažniausiai ilgą laiką sklaidos defektai simptomų nesukelia, tačiau ilgainiui gali būti kliniškai reikšminga AV stenozė ir (ar) nesandarumas kartu su aortos šaknies pažaida [1]. Genetinių ir hemodinaminių veiksnių nulemti struktūriniai AV pakitimai trikdo kraujo tėkmę per vožtuvą, lemia turbulencinès tėkmès atsiradimą, kuri sukelia pokyčius aortos sienelëje, vystosi segmentinès aortos aneurizmos, todèl didejja ūmios aortos disekacijos rizika $[5,6]$.

Tyrimo tikslas - remiantis naujausios mokslinès literatūros duomenimis, apžvelgti dviburio aortos vožtuvo etiologinius veiksnius, diagnostikos ir chirurginio gydymo galimybes.

\section{Tyrimo medžiaga ir metodai}

Naujausios mokslinès literatūros paieška buvo atlikta $\mathrm{Pu}$ bMed ir UpToDate mokslinėse duomenų bazėse. İ sisteminę apžvalgą įtraukta 30 straipsnių, kuriuose aprašoma dviburio aortos vožtuvo etiologija, diagnostika ir chirurginis gydymas.

\section{Tyrimo rezultatai}

Etiologija. DAV daugeliu atvejų yra paveldimi autosominiu dominantiniu būdu, esant kintančiam penetrantiškumui. Specifinès genetinès priežastys nèra žinomos, tačiau DAV morfologija dažniausiai nustatoma kartu su Notch1 geno mutacija [7]. Remiantis A. Hales ir V. Mahle atlikto klinikio tyrimo rezultatais, nustatyta 10 proc. paveldejimo tikimybè tiriamojo, kuris turi DAV morfologiją, pirmos eilès giminaičiams [8]. DAV morfologijai būdinga kylančiosios aortos aneurizma - aortopatija, paveldima autosominiu dominantiniu būdu, esant žemam penetrantiškumui [9]. Profilaktinis 2D echokardiografinis patikrinimas turi būti atliktas paciento, kuris turi DAV morfologiją, pirmos eilès giminaičiams (IIa klasès rekomendacija) [10].

Morfologija. DAV fenotipas gali būti skirtingas priklausomai nuo sklaidos. DAV fenotipą nusako Sievers klasifikacija. Pagal burių sklaidą, DAV gali būti pilnas simetrinis arba asimetrinis su rudimentine pseudokomisūra ir siūle (angl. raphe) [11]. Echokardiografinis DAV ištyrimas techniškai sudètingas. Net ir esant trims komisūroms, negalima teigti, kad AV yra triburis, kol nepaneigtas burių sklaidos defektas - burių suaugimas [12]. Dažniausiai suauga kairioji ir 
dešinioji vainikinès burès, rečiau kairioji ar dešinioji burè su nevainikine bure [13].

Klinikinės išraiškos. Klinikinė eiga (simptomai) priklauso nuo AV funkcijos ir gretutinių kardiovaskulinès sistemos pakitimų. Funkciškai normalus DAV simptomų nesukelia, todèl gali būti randamas atsitiktinai [14]. Stenozę ir (ar) nesandarumą sukeliantis DAV gali kurị laiką išlikti besimptomis arba sukelti tam tikrus simptomus, būdingus ne tik kardiovaskulinei sistemai: pasunkèjęs kvėpavimas, fizinio krūvio netoleravimas, galvos svaigimas [1].

Diagnostika. Pirmaeilis tyrimas DAV morfologijai nustatyti $-2 \mathrm{D}$ echokardiografinis transtorakalinis ištyrimas, kurio metu randami būdingi pakitimai: sistolinis kupolavimas, ekscentrinè regurgitacinè kraujo tèkmè, burių audinio perteklius (prolapsas), siūlè tarp burių, elipsès formos AV žiedas sistolès metu ir kylančiosios aortos dilatacija [1]. 2D echokardiografijos jautrumas nustatant DAV morfologiją yra 78-92 proc., specifiškumas - 96 procentai [15]. Pacientams, turintiems DAV morfologiją, turi būti atliekama 2D echokardiografija per krūtinès ląstą, kurios metu ịvertinama AV morfologija, stenozès ar nesandarumo sunkumas, išmatuojami aortos šaknies (aortos sinusų) ir kylančiosios aortos diametrai [16]. Galima papildomai atlikti magnetinio rezonanso tomografijos (MRT) tyrimą, kuris puikiai vizualizuoja širdies struktūras ir didesnes kraujagysles, vertina AV bei kairiojo skilvelio funkciją. MRT tyrimas neturi radiacinès apšvitos, todèl parenkamas, kai pacientui reikalingi kartotiniai tyrimai [10]. MRT tyrimo jautrumas yra 100 proc., specifiškumas - 94 procentai. [17]. Esant kontraindikacijų atlikti MRT tyrimą, gali būti atliekamas kompiuterinès tomografijos (KT) tyrimas [10], jautrumas - 94 proc., specifiškumas - 100 procentų [18].

Labai svarbus yra pacientų, turinčių DAV morfologiją, stebejjimas dèl progresuojančios AV disfunkcijos (stenozès ir (ar) nesandarumo), dèl aortos segmentinès dilatacijos (padidejjusios rizikos disekacijos tikimybès) [1]. Echokardiografinių kontrolinių tyrimų dažnis priklauso nuo AV, aortos šaknies ir (ar) kylančiosios aortos patologijos, paciento amžiaus, klinikinio pasireiškimo [10].

Infekcinis endokarditas. DAV didina infekcinio endokardito (IE) riziką [19]. V. Becerra-Muñoz su kolegomis atliktame retrospektyviniame tyrime, iš 328 pacientų, sirgusių IE, 5,5 proc. turejjo DAV [20]. Esant DAV morfologijai, didesnè rizika IE ịvykių, lyginant su triburiu AV, todèl reikalingas chirurginis gydymas [21]. Pacientams, turintiems DAV morfologiją, rekomenduojama atliekant invazines odontologines prodedūras skirti profilaktinę antibiotikoterapiją [22].

Chirurginis gydymas. Europos kardiologų draugijos 2020 metų igimtų širdies ydų rekomendacijos [23] nurodo tokias chirurginio DAV gydymo indikacijas: 1) ryški simp- tominè AV stenozė, 2) ryški besimptomè $\mathrm{AV}$ stenozè, kai kairiojo skilvelio išstūmimo frakcija (KSIF) $\leq 50$ proc., 3 ) ryškus simptominis AV nesandarumas, 4) ryškus besimptomis AV nesandarumas, kai KSIF $\leq 50$ proc., 5) ryškus besimptomis AV nesandarumas, kai KSIF $>50$ proc., tačiau stebimas didelio laipsnio KS išsiplètimas (KS galinis diastolinis dydis $>70 \mathrm{~mm}$ arba KS galinis sistolinis dydis $>50$ $\mathrm{mm}$ arba galinio sistolinio dydžio indeksas $>25 \mathrm{~mm} / \mathrm{m}^{2}$ ).

H. Bentall ir A. De Bono 1968 metais aprašyta chirurginè metodika iki šiol laikoma auksiniu standartu, gydant skirtingos patologijos AV pakitimus (AV stenozė ar nesandarumas). Taikant šią metodiką, aortos šaknis ir AV yra pilnai protezuojami sudètiniu (mechaniniu ar biologiniu) protezu [24]. Mechaninis vožtuvas užtikrina ilgaamžį funkcionavimą ir mažą kartotinių intervencijų skaičių, todèl parenkamas jaunesniems pacientams. Pacientams su mechaniniu AV reikalinga viso gyvenimo trukmès antikoaguliantų terapija, kuri lemia kraujavimą ir tromboembolines komplikacijas vèlyvuoju pooperaciniu laikotarpiu [25]. Gyvenimo trukmès antikoaguliantų terapija nereikalinga naudojant biologini protezą, jeigu nėa gretutinių ritmo ir laidumo sutrikimų, tačiau dažnai jauniems ir aktyviems žmonèms stebima greita biologinių protezų degeneracija [26].

Esant AV nesandarumui, šiuolaikinèje klinikinèje praktikoje orientuojamasi i AV išsaugančias operacijas, dèl mažesnių su vožtuvais susijusių komplikacijų rodiklių ir geresnio išgyvenamumo, nesant viso gyvenimo trukmės antikoaguliantų terapijos poreikio [27]. Dažniausiai taikomos dvi pagrindinès operacinès metodikos - AV reimplantacijos (T. David metodika) [28] ir remodeliavimo (M.Yacoub metodika) [29]. T. David su kolegomis 29 metu laikotarpio tyrime dalyvavo 465 tiriamieji (67 (14,4 proc.) turèjo DAV morfologiją), kuriems buvo atlikta David procedūra - 3 pacientams (4,5 proc.), turintiems DAV morfologiją, buvo reikalingas AV protezavimas 6, 9 ir 10 metų laikotarpiais dèl AV pokyčių [30].

LSMUL KK širdies, krūtinès ir kraujagyslių chirurgijos klinikoje 2004-2020 metais buvo atliktos 110 operacijų pagal T. David metodiką, iš kurių 40 dèl DAV. Pacientų amžiaus vidurkis $42,7 \pm 11,8$ metai. Ankstyvuoju pooperaciniu laikotarpiu mirè 1 pacientas dèl aortos disekacijos komplikacijų. Vèlyvuoju pooperaciniu laikotarpiu nustatytas 100 proc. išgyvenamumas.

\section{Išvados}

1. Dažniausiai DAV morfologija paveldima autosominiu dominantiniu būdu ir nustatoma kartu su Notch1 geno mutacija.

2. Pirmaeilis tyrimas DAV morfologijai nustatyti yra dvimatis echokardiografinis ištyrimas per krūtinès ląstą. Esant 
indikacijų, gali būti atliekamas ir magnetinio rezonanso ar kompiuterinès tomografijos tyrimas.

3. Chirurginio AV patologijos gydymo auksinis standartas yra H. Bentall operacija, kurios pagrindinis trūkumas - viso gyvenimo trukmės antikoaguliantų terapijos poreikis, lemiantis kraujavimą vèlyvuoju pooperaciniu laikotrapiu.

4. AV išsaugančių operacijų mažesni su vožtuvais susijusių komplikacijų rodikliai ir geresnis išgyvenamumas, nesant viso gyvenimo trukmès antikoaguliantų terapijos poreikio, todèl jos vis plačiau taikomos klinikinejje praktikoje.

\section{Literatūra}

1. Siu SC, Silversides CK. Bicuspid aortic valve disease. J Am Coll Cardiol 2010;55(25):2789-800.

https://doi.org/10.1016/j.jacc.2009.12.068

2. Li Y, Wei X, Zhao Z, Liao Y, He J, Xiong T, et al. Prevalence and complications of bicuspid aortic valve in chinese according to echocardiographic database. Am J Cardiol 2017;120(2):287-91. https://doi.org/10.1016/j.amjcard.2017.04.025

3. Shah SY, Higgins A, Desai MY. Bicuspid aortic valve: basics and beyond. Cleve Clin J Med 2018;85(10):779-84.

https://doi.org/10.3949/ccjm.85a.17069

4. Sachdev V, Matura LA, Sidenko S, Ho VB, Arai AE, Rosing DR, et al. Aortic valve disease in turner syndrome. J Am Coll Cardiol 2008;51(19):1904-9.

https://doi.org/10.1016/j.jacc.2008.02.035

5. Freeze SL, Landis BJ, Ware SM, Helm BM. Bicuspid aortic valve: a review with recommendations for genetic counseling. Journal of Genetic Counseling. Springer New York LLC 2016;25:1171-8.

https://doi.org/10.1007/s10897-016-0002-6

6. Rodrigues I, Agapito AF, De Sousa L, Oliveira JA, Branco LM, Galrinho A, et al. Bicuspid aortic valve outcomes. Cardiol Young 2017;27(3):518-29.

https://doi.org/10.1017/S1047951116002560

7. Kostina AS, Uspensky VE, Irtyuga OB, Ignatieva EV, Freylikhman O, Gavriliuk ND, et al. Notch-dependent EMT is attenuated in patients with aortic aneurysm and bicuspid aortic valve. Biochim Biophys Acta - Mol Basis Dis 2016;1862(4):733-40. https://doi.org/10.1016/j.bbadis.2016.02.006

8. Hales AR, Mahle WT. Echocardiography screening of siblings of children with bicuspid aortic valve. Pediatrics 2014;133(5). https://doi.org/10.1542/peds.2013-3051

9. Loscalzo ML, Goh DLM, Loeys B, Kent KC, Spevak PJ, Dietz HC. Familial thoracic aortic dilation and bicommissural aortic valve: a prospective analysis of natural history and inheritance. Am J Med Genet Part A 2007;143(17):1960-7.

https://doi.org/10.1002/ajmg.a.31872

10. Stout KK, Daniels CJ, Aboulhosn JA, Bozkurt B, Broberg CS, Colman JM, et al. 2018 AHA/ACC guideline for the management of adults with congenital heart disease: a report of the American College of Cardiology/American Heart Association task force on clinical practice guidelines. Circulation 2019;139(14):e698-800.

https://doi.org/10.1161/CIR.0000000000000602

11. Sievers HH, Schmidtke C. A classification system for the bicuspid aortic valve from 304 surgical specimens. J Thorac Cardiovasc Surg 2007;133(5):1226-33.

https://doi.org/10.1016/j.jtcvs.2007.01.039

12. Michelena HI, Prakash SK, Corte A Della, Bissell MM, Anavekar N, Mathieu P, et al. Bicuspid aortic valve identifying knowledge gaps and rising to the challenge from the international bicuspid aortic valve consortium (BAVCON). Circulation 2014;129: 2691-704.

https://doi.org/10.1161/CIRCULATIONAHA.113.007851

13. De Kerchove L, Mastrobuoni S, Froede L, Tamer S, Boodhwani M, Van Dyck M, et al. Variability of repairable bicuspid aortic valve phenotypes: towards an anatomical and repair-oriented classification. Eur J Cardio-thoracic Surg 2019;56(2):351-9. https://doi.org/10.1093/ejcts/ezz033

14. Pedersen MW, Groth KA, Mortensen KH, Brodersen J, Gravholt $\mathrm{CH}$, Andersen NH. Clinical and pathophysiological aspects of bicuspid aortic valve disease. Cardiol Young 2019;29(1):1-10. https://doi.org/10.1017/S1047951118001658

15. Hillebrand M, Koschyk D, Hark P Ter, Schüler H, Rybczynski M, Berger J, et al. Diagnostic accuracy study of routine echocardiography for bicuspid aortic valve: a retrospective study and meta-analysis. Cardiovasc Diagn Ther 2017;7(4):367-79. https://doi.org/10.21037/cdt.2017.05.03

16. Michelena HI, Chandrasekaran K, Topilsky Y, Messika-Zeitoun D, Della Corte A, Evangelista A, et al. The bicuspid aortic valve condition: the critical role of echocardiography and the case for a standard nomenclature consensus. Progress in Cardiovascular Diseases 2018;61(5-6):404-415.

https://doi.org/10.1016/j.pcad.2018.11.003

17. Gleeson TG, Mwangi I, Horgan SJ, Cradock A, Fitzpatrick P, Murray JG. Steady-state free-precession (SSFP) cine MRI in distinguishing normal and bicuspid aortic valves. J Magn Reson Imaging 2008;28(4):873-8.

https://doi.org/10.1002/jmri.21547

18. Tanaka R, Yoshioka K, Niinuma H, Ohsawa S, Okabayashi H, Ehara S. Diagnostic value of cardiac CT in the evaluation of bicuspid aortic stenosis: comparison with echocardiography and operative findings. AJR Am J Roentgenol 2010;195(4):895-9. https://doi.org/10.2214/AJR.09.3164

19. Michelena HI, Katan O, Suri RM, Baddour LM, EnriquezSarano M. Incidence of infective endocarditis in patients with bicuspid aortic valves in the community. Mayo Clinic Proceedings 2016;91(1):122-3.

https://doi.org/10.1016/j.mayocp.2015.10.011

20. Becerra-Muñoz VM, Ruíz-Morales J, Rodríguez-Bailón I, Sánchez-Espín G, López-Garrido MA, Robledo-Carmona J, et al. Endocarditis infecciosa sobre válvula aórtica bicúspide: 
características clínicas, complicaciones y pronóstico. Enferm Infecc Microbiol Clin 2017;35(10):645-50.

https://doi.org/10.1016/j.eimc.2016.06.017

21. Tribouilloy C, Rusinaru D, Sorel C, Thuny F, Casalta JP, Riberi A, et al. Clinical characteristics and outcome of infective endocarditis in adults with bicuspid aortic valves: a multicentre observational study. Heart 2010;96(21):1723-9.

https://doi.org/10.1136/hrt.2009.189050

22. Nishimura RA, Otto CM, Bonow RO, Carabello BA, Erwin JP, Guyton RA, et al. 2014 AHA/ACC guideline for the management of patients with valvular heart disease: a report of the American college of cardiology/American heart association task force on practice guidelines. J Am Coll Cardiol 2014;63(22).

https://doi.org/10.1161/CIR.0000000000000029

23. Baumgartner H, De Backer J, Babu-Narayan S V, Budts W, Chessa M, Diller G-P, et al. 2020 ESC guidelines for the management of adult congenital heart disease. Eur Heart J 2020; ehaa554.

https://doi.org/10.1093/eurheartj/ehaa701

24. Bentall H, De Bono A. A technique for complete replacement of the ascending aorta. Thorax 1968;23(4):338-9.

https://doi.org/10.1136/thx.23.4.338

25. Leontyev S, Schamberger L, Davierwala PM, Von Aspern K, Etz C, Lehmann S, et al. Early and late results after David vs Bentall procedure: a propensity matched analysis. Ann Thorac Surg 2020;110(1):120-6.

https://doi.org/10.1016/j.athoracsur.2019.10.020

26. Wang M, Furnary AP, Li HF, Grunkemeier GL. Bioprosthetic aortic valve durability: a meta-regression of published studies. Annals of Thoracic Surgery 2017;104(3):1080-7. https://doi.org/10.1016/j.athoracsur.2017.02.011

27. Ouzounian M, Rao V, Manlhiot C, Abraham N, David C, Feindel CM, et al. Valve-sparing root replacement compared with composite valve graft procedures in patients with aortic root dilation. J Am Coll Cardiol 2016;68(17):1838-47.

https://doi.org/10.1016/j.jacc.2016.07.767
28. David TE, Feindel CM. An aortic valve-sparing operation for patients with aortic incompetence and aneurysm of the ascending aorta. J Thorac Cardiovasc Surg 1992;103(4):617-22. https://doi.org/10.1016/S0022-5223(19)34942-6

29. Sarsam MAI, Yacoub M. Remodeling of the aortic valve anulus. J Thorac Cardiovasc Surg 1993;105(3):435-8. https://doi.org/10.1016/S0022-5223(19)34225-4

30. David TE, David CM, Ouzounian M, Feindel CM, Lafreniere-Roula M. A progress report on reimplantation of the aortic valve. J Thorac Cardiovasc Surg 2020. https://doi.org/10.1016/j.jtcvs.2020.07.121

\section{BICUSPID AORTIC VALVE: ETIOLOGY, DIAGNOSIS, SURGICAL TREATMENT \\ D. Karčiauskas, V. Zieniūtė}

Keywords: bicuspid aortic valve, congenital heart disease, infective endocarditis, heart surgery.

\section{Summary}

Bicuspid aortic valve (BAV) is one of the most common types of congenital heart disease, which can be isolated lesion or associated with other congenital cardiovascular pathologies or genetic syndromes. BAV morphology is hemodynamically important because it disrupts blood flow through the valve and causes turbulent flow, which tirggers changes in the aortic wall. First-line test to diagnose BAV morphology is two-dimensional (2D) transthoracic echocardiography. Patients with a functionally normal BAV can ramain asymptomatic for a long period of time, however eventually may develop severe aortic stenosis or aortic regurgitation with a need for cardiac surgery. The gold standart surgical treatment of patiens with aortic valve pathology is Bentall procedure, however valve-sparing root replacement is alternative to Bentall procedure because of lower risk of valve-associated events and superior survival with no need for lifelong anticoagulation therapy.

Correspondence to: viktorijazieniute@gmail.com

Gauta 2020-11-09 